\title{
The potential value of integrated natriuretic peptide and echo-guided heart failure management
}

\author{
Maria Chiara Scali*, Anca Simioniuc, Frank Lloyd Dini and Mario Marzilli
}

\begin{abstract}
There is increasing interest in guiding Heart Failure (HF) therapy with Brain Natriuretic Peptide (BNP) or N-terminal prohormone of Brain Natriuretic Peptide (NT-proBNP), with the goal of lowering concentrations of these markers (and maintaining their suppression) as part of the therapeutic approach in HF. However, recent European Society of Cardiology (ESC) and American Heart Association/ American College of Cardiology (AHA/ACC) guidelines did not recommend biomarker-guided therapy in the management of HF patients. This has likely to do with the conceptual, methodological, and practical limitations of the Natriuretic Peptides (NP)-based approach, including biological variability, slow time-course, poor specificity, cost and venipuncture, as well as to the lack of conclusive scientific evidence after 15 years of intensive scientific work and industry investment in the field. An increase in NP can be associated with accumulation of extra-vascular lung water, which is a sign of impending acute heart failure. If this is the case, an higher dose of loop diuretics will improve symptoms. However, if no lung congestion is present, diuretics will show no benefit and even harm. It is only a combined clinical, bio-humoral (for instance with evaluation of renal function) and echocardiographic assessment which may unmask the pathophysiological (and possibly therapeutic) heterogeneity underlying the same clinical and NP picture. Increase in B-lines will trigger increase of loop diuretics (or dialysis); the marked increase in mitral insufficiency (at baseline or during exercise) will lead to increase in vasodilators and to consider mitral valve repair; the presence of substantial inotropic reserve during stress will give a substantially higher chance of benefit to beta-blocker or Cardiac Resynchronization Therapy (CRT). To each patient its own therapy, not with a "blind date" with symptoms and NP and carpet bombing with drugs, but with an open-eye targeted approach on the mechanism predominant in that individual patient. A monocular, specialistic, unidimensional approach to HF can miss its pathogenetic and clinical complexity, which only can be overcome with an integrated, versatile and tailored approach.
\end{abstract}

Keywords: Biomarkers, B-lines, Echocardiography, Heart Failure, Natriuretic peptide

\section{Introduction}

Approximately 5.1 million people $>20$ years old in the USA live with chronic Heart Failure (HF). An estimated 670,000 new cases are diagnosed annually among USA adults $>45$ years old, and HF causes or contributes to almost 300,000 deaths each year. Various demographic trends, including the aging of the population and greater likelihood of survival after acute myocardial infarction, suggest that the prevalence of HF will likely continue to

\footnotetext{
*Correspondence: chiara_scali@yahoo.it

Unità Operativa Malattie Cardiovascolari 1, Dipartimento Cardio-Toracico e Vascolare, Azienda Ospedaliera-Universitaria Pisana, Via Paradisa, 2. 56124 Pisa, Italy
}

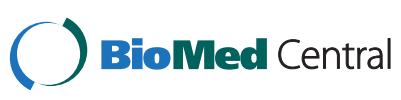

(c) 2014 Scali et al.; licensee BioMed Central Ltd. This is an Open Access article distributed under the terms of the Creative Commons Attribution License (http://creativecommons.org/licenses/by/4.0), which permits unrestricted use, distribution, and reproduction in any medium, provided the original work is properly credited. The Creative Commons Public Domain Dedication waiver (http://creativecommons.org/publicdomain/zero/1.0/) applies to the data made available in this article unless otherwise stated increase; indeed, the American Heart Association (AHA) estimates that by 2030, HF prevalence will increase by $25 \%$ over 2013 estimates [1].

Although there have been significant advances in the treatment of HF, morbidity and mortality remain high. Pharmacologic regimens have become increasingly complex, and standard therapy now often consists of multiple drugs (angiotensin-converting enzyme inhibitors, angiotensin receptor blockers, beta-blockers, aldosterone antagonists, diuretics, digoxin, and, in African-American patients, hydralazine and isosorbide dinitrate). The economic impact is significant as well and costs of HF hospitalizations amount to $\$ 29$ billion/year in the USA 
alone. Given these epidemiologic and economic pressures, there is increasing interest in using cardiovascular biomarkers for a personalized medicine approach to more effectively guide diagnosis, risk stratification, and therapy [2]. This review aims to provide a reassessment of pathophysiological rationale and existing evidences, highlighting the value and limitations of the currently employed clinical approach based on Natriuretic Peptides (NP), and outline the potential of an alternative, cardiovascular ultrasoundbased approach for personalized treatment of HF.

\section{Biomarkers in HF therapy}

In many disease states, drug selection and dosage are strictly dependent from biomarkers [3]. Classic experience with diabetes has taught clinicians to adjust hypoglycemic agents dose to blood glucose levels. The idea of transferring a similar approach to HF may appear attractive. Unfortunately, in HF some basic requirements for such a transposition are missing. HF is a complex systemic syndrome and HF symptoms do not have a consistent relation with severity of Left Ventricular (LV) dysfunction, but express malfunction of adaptive mechanisms, including the natriuretic peptide system, the renin-angiotensinaldosterone system, and the autonomic nervous system. There is no reason to believe that these systems have a uniform behavior in different forms of HF. Conversely, drug therapy of HF has assumed a uniform response to treatment, irrespective of the pathogenetic mechanism. Based on this oversimplification, HF from global dysfunction of the cardiac muscle, such as in dilated cardiomyopathy, is expected to receive the same treatment as HF associated with regional wall dysfunction, such as in ischemic cardiomyopathy, and even HF in patients with valvular heart disease or hypertrophic cardiomyopathy. Moreover, current guidelines do not consider adjustment of drug selection and dosage to severity of HF symptoms. All symptomatic patients are expected to receive all the agents proven to be beneficial in Randomized Clinical Trials (RCT), at the dosage prescribed in the RCTs, with limited if any room to tailoring of therapy to patient's need.

Recognizing the heterogeneity of HF and dissecting it into different therapeutic groups would improve the targeting of interventions, which in turn could improve response rates and avoid adverse effects in patients unlikely to benefit. Studies have demonstrated the need to target specific phenotypes based on this heterogeneity [4]. Moreover accurate targeting of therapies could allow the focused use of the drugs most likely to be effective and safe in a given individual, thereby potentially enhancing compliance, improving outcomes, and lowering the cost of medical care. Based on these concepts, it appears that the limitations of current approaches in guiding HF therapy express more the limitations of our understanding of the pathogenesis of these conditions and the simplifications of current therapeutic approach, than intrinsic inadequacy of the employed biomarkers. Heterogeneity in response to therapies warrants further research to identify biomarkers that can not only stratify risk but also identify the underlying disease process that may be targeted by specific therapies.

\section{Biology of NP in HF}

Circulating levels of NP are normally very low in healthy individuals. In response to increased myocardial wall stress due to volume- or pressure-overload states (such as in HF), the Brain Natriuretic Peptide (BNP) gene is activated in cardiomyocytes. This results in the production of an intracellular precursor propeptide (proBNP108); further processing of this propeptide results in release of the biologically inert aminoterminal fragment called N-terminal prohormone of Brain Natriuretic Peptide (NT-proBNP)and the biologically active BNP [5]. In addition, a significant portion of BNP or NT-proBNP detected by current assays includes uncleaved proBNP108, whereas BNP concentrations also include the detection of various subfragments that arise from the degradation of the intact BNP hormone. The biological activity of BNP includes stimulation of natriuresis and vasorelaxation; inhibition of renin, aldosterone, and sympathetic nervous activity; inhibition of fibrosis; and improvement in myocardial relaxation. Although released in a 1:1 ratio, the measured NT-proBNP level is higher than that of BNP, in part because NTproBNP is passively cleared from the circulation more slowly (half-life of 120 versus 20 minutes). Unlike BNP, NT-proBNP is not cleared by NP receptors or neutral endopeptidases. Rather, NT-proBNP is cleared by various organs, including the skeletal tissue, liver, and kidneys. A common misconception is that NT-proBNP is more dependent on renal function for clearance than is BNP; both are equally cleared by the kidneys.

BNP and NT-proBNP levels are increased in HF, and correlate well with ventricular wall stress and severity of HF. The Breathing Not Properly Multinational Study and the Pro-BNP Investigation of Dyspnea in the Emergency Department showed that NP levels were more accurate for diagnosis or exclusion of Acute Decompensated Heart Failure (ADHF) than clinical judgment, particularly in the context of diagnostic uncertainty. When added to comprehensive clinical assessment, BNP and NT-proBNP are both incrementally useful for diagnosis of ADHF, and both are endorsed in current practice guidelines for HF evaluation (particularly when diagnostic indecision is present). Elevated BNP (above approximately $125 \mathrm{pg} / \mathrm{mL}$ ) or NT-proBNP (above approximately $1000 \mathrm{pg} / \mathrm{mL}$ ) values are prognostically meaningful in chronic $\mathrm{HF}$, and a rising pattern is predictive of impending adverse outcome, irrespective of other subjective and objective prognostic 
metrics. Furthermore, therapies that are favorable for chronic HF (such as beta-blockers, vasodilators, or aldosterone blockers) tend to lower concentrations of BNP or NT-proBNP.

Thus, there is increasing interest in guiding HF therapy with BNP or NT-proBNP, with the goal of lowering concentrations of these markers (and maintaining their suppression) as part of the therapeutic approach in HF. However, recent European Society of Cardiology (ESC) and AHA/American College of Cardiology (ACC) guidelines [6,7] did not recommend biomarker-guided therapy in the management of HF patients. Therefore, in contrast to oncology, biomarker approaches are not yet routinely used in the management of HF. This has likely to do with the conceptual, methodological, and practical limitations of the NP-based approach, as well as to the lack of conclusive scientific evidence after 15 years of intensive scientific work and industry investment in the field.

\section{Limitations of NP approach}

Limitations of NP-based approach include major limitations (including biological variability, slow time-course, poor specificity and lack of conclusive scientific evidences) and minor weaknesses - such as cost and venipuncture.

\section{Biological variability}

The term "biological variability" refers to the extent of changes of a biomarker in a stable physiological state. In practice, biological variability indicates the change in measurement that have a biological significance. Both BNP and NT-proBNP are limited in their clinical use by an excess variability that reaches $40 \%$ for BNP and $25 \%$ for NT-proBNP [8]. Given a threshold of $1000 \mathrm{pg} / \mathrm{mL}$ for the BNP-based diagnosis of cardiac origin of dyspnea, this variability implies that measurements from $600 \mathrm{pg} / \mathrm{mL}$ to $1400 \mathrm{pg} / \mathrm{ml}$ are biologically equivalent. The negative implications of such variations are obvious in the followup of HF patients. For NT-proBNP, the clinical variability is less wide, but still clinically relevant around $25 \%$. In the real world this makes difficult or impossible to estimate if changes BNP plasma levels that remain within this wide range express real changes of patient conditions or only spontaneous biological variability. Trials have used a fixed [9-15] or individualized [16-18] NP target, with no clear difference in results. Six trials testing the value of NT-proBNP used target values ranging from 4000 to $2200 \mathrm{mg} / \mathrm{L}$, with greater benefit observed with higher target values, suggesting that the more aggressive efforts to reduce NP values are not necessarily better.

\section{Time course of BNP changes in response to therapy}

Ideally, a biomarker should reflect as quickly as possible improvement or worsening of patients' conditions, either spontaneous or therapy-induced. A fast response is even more essential in critical conditions such as decompensated HF. Unfortunately, data from studies of serial BNP measurements suggest that concentrations of NTproBNP require from 2 to 4 weeks after a therapy change to stabilize [19]. Obviously this makes impossible to rely on these measurements in unstable conditions.

\section{Poor specificity}

Most cardiologists believe that BNP and NT-proBNP directly reflects variations in volume of cardiac chambers. This is certainly true, but by no means a specific finding. In fact, BNP and NT-proBNP levels change also in response to arrhythmias, myocardial ischemia, valvular heart disease, changes of filling pressures, diastolic function, only to mention cardiac factors. Also non-cardiac factors, including age, sex, body mass index and genetic factors are important confounders, as are pulmonary hypertension, pulmonary embolism and chronic kidney disease [20]. NP levels correlate imperfectly with measured filling pressures and may remain elevated in the absence of significant congestion. Some drugs, such as beta-blockers, may increase Ejection Fraction (EF) and improve prognosis, but also increase NP levels through direct pharmacological mechanisms unrelated to effects pump function [21]. Not all causes that elevate NP values are cardiac in origin, and in addition not all cardiac causes of elevation of NP relate to increase in LV pressures and/or volumes. In this era of progressively aging of the HF populations and growing prevalence of comorbidities, the specificity and hence the diagnostic value of NP is strongly challenged.

\section{Lack of conclusive scientific evidence}

In the era of evidence based medicine, no guideline can be proposed if not supported by sound data. More than 9 trials have been completed and published since when NP levels have been proposed to guide HF therapy. The natriuretic peptide guided- strategy is associated with reduction in all-couse mortality and HF- related hospitalization as well as with the risk of readmission for HF worsening, as shown by recent meta-analyses. However further evidence is still needed to support a more general use of NP, since the results of this trial are inconclusive as regards cardiac death [22,23].

The results of these trials are inconsistent and inconclusive. The clear demonstration of this statement is that an additional trial is being conducted and eagerly waited by both supporters and skeptics (Guiding evidence based therapy using biomarkers intensified treatment, GUIDEIT). The mixed results are after all not so surprising in the light of previous limitations. NP increase is determined by a spectrum of different pathophysiological conditions (from lung congestion to systolic dysfunction to increase of mitral insufficiency during exercise) and triggers a monotonous therapeutic response, of questionable benefit 
in the individual patient, and typically associated with a relative increase in the use of angiotensin-enzyme inhibitors, beta-blockers, angiotensin receptor blockers, and spironolactone over standard, symptom-guided care. If the physician relies on NP levels to assess volume status, the choice of dose escalation of loop diuretics in patients without pulmonary congestion may increase the rate of hypotension, renal dysfunction and adverse outcome.

\section{Cost}

HF poses a heavy economic burden on western economies, being one of the largest contributors to health cost. NP measurements, though not very expensive add to the overall cost of HF therapy. The additional cost for each BNP measurement varies largely from hospital to hospital, and averages $30 €$. NT-proBNP measurement is generally more expensive. Given the need for serial measurements and the number of the HF populations, it is easy to estimate how much a systematic NP based approach would impact on health cost. That is why a generalized use of NP based therapy is not justified until conclusive evidence is provided of its cost-effectiveness.

\section{Need for venipuncture}

This may appear as a minor nuisance for doctor and patients, but sometimes the blood sampling may be a challenging task in elderly, fragile, obese patients.

Based on the concepts expressed in preceding paragraphs, therapy of HF might be reconsidered. An effort should be made to identify the agents and the dosages to be prescribed to patients according to the etiology of the HF and to the severity of symptoms, abandoning the current strategy of giving all agents, at the highest tested dose, to all patients. It is conceivable that in this context, patients can be identified in whom NP dosage may provide a good guidance to therapy, and patients that do not have benefit from such approach. This hypothesis would become even more appealing if biomarkers with less biological variability, greater specificity and faster time response can become available.

\section{The potential role of echocardiographic biomarkers in heart failure}

Echocardiography-derived parameters can fulfill the definition of biomarkers since in 2001, a working group of the National Institutes of Health standardized the definition of a biomarker as a "characteristic that is objectively measured and established as an indicator of normal biological pathologic processes, pathogenetic processes, or pharmacologic responses to a therapeutic intervention". A biomarker may be measured on a biosample (such as a blood test, for instance, the D-dimer as a biomaker of vulnerable blood) or it may be an imaging test (for instance, echocardiogram for vulnerable myocardium) [24].
The ideal candidate biomarker should fulfill some basic pre-requisites: 1) easily defined, safe, and reproducible in each patient; 2) appropriate therapeutic counter measures should be available to reset the abnormal biomarker values towards normal range; 3) the biomarker-triggered therapy change should improve outcome; 4) the biomarkerdriven approach should provide an improved benefit and cost-benefit over standard approach.

A classical example of a powerful risk marker unsuitable as a therapeutic target is serum sodium concentration. The lower the sodium concentration, the higher the degree of neuro-hormonal activation and the poorer the prognosis, but treatment aimed at normalizing sodium levels will not improve clinical outcomes [25].

Echo biomarkers in HF show several prerequisites for being useful. According to the recent ESC guidelines on $\mathrm{HF}$, echocardiography is the imaging method of choice for reasons of accuracy, availability (including portability), safety and cost. The more frequently used echo parameters are reported in Table 1 . They are certainly simple to measure, even with pocket-size instruments, and reasonably reproducible in expert hands. They are associated with strong prognostic power, and several have shown independent and incremental prognostic value over standard clinical and bio-humoral predictors. They explore different and complementary aspects of HF pathophysiology including: LV function (usually with EF with biplane Simpson method, or with more accurate but also more costly and technically demanding Real Time 3D); right ventricular function (with tricuspid annular plane systolic excursion); diastolic function (with left atrial volume index, E/e' ratio, $\mathrm{E}$ wave deceleration time); extravascular lung water (exploring pulmonary congestion with lung B-lines); mitral-insufficiency; pulmonary hypertension (with pulmonary artery systolic pressure). Another extremely attractive field is the assessment of the behavior of these markers during exercise. Stress echo applications beyond coronary artery disease are emerging as an attractive field, and there is no question that a moderate mitral insufficiency becoming severe during stress and accompanied by B-lines and pulmonary hypertension can make a mitral valve repair an attractive therapeutic option. However, also in these cases the evidences on points 3 and 4 on the chain of biomarker validation are conspicuously lacking to date.

\section{Limitations of echocardiographic approach}

In spite of the unsurpassed appeal in terms of low cost, widespread access, versatility of the information provided, there are limitations of echo-based approach, including dependence on patient's acoustic window, operator's expertise and lack of sufficient evidence based-data in echo-driven management of HF patients [6]. 
Table 1 Common echocardiographic and lung sonography abnormalities in patients with heart failure

\begin{tabular}{|c|c|c|}
\hline Measurement & Abnormality & Clinical implications \\
\hline \multicolumn{3}{|c|}{ Parameters related to systolic function } \\
\hline LV ejection fraction & Reduced $(<50 \%)$ & LV global systolic dysfunction \\
\hline RV Tapse & Reduced (<16 mm) & RV global systolic dysfunction \\
\hline \multicolumn{3}{|c|}{ Parameters related to diastolic function } \\
\hline E/e' ratio & Increased (>15) & High LV filling pressure \\
\hline \multicolumn{3}{|c|}{ Parameters related to pulmonary congestion } \\
\hline B-lines & $>5$ in anterior chest scan & Extravascular lung water \\
\hline \multicolumn{3}{|c|}{ Parameters related to valvular function } \\
\hline Mitral valve dysfunction & Severe mitral regurgitation & Cause/consequences of $\mathrm{HF}$ \\
\hline \multicolumn{3}{|c|}{ Parameters related to contractile reserve } \\
\hline Global LV function during stress & No contractile reserve & Unresponsive scar tissue \\
\hline
\end{tabular}

LV, left ventricle; RV, right ventricle; TAPSE, tricuspid annular plane systolic excursion. Adapted from ESC 2012, ref 17.

\section{Dependence on patient's window}

Although last generation echocardiographic instruments allow satisfactory to excellent imaging in $>90 \%$ of patients referred to echocardiography lab, poor acoustic windows exist in a significant portion of subjects, for instance with morbid obesity or lung disease. The use of intravenous contrast agents for endocardial border enhancement and better left ventricular cavity recognition is indicated whenever $\geq 2$ contiguous segments are not adequately visualized [26] and considerably increases the success rate of echocardiographic imaging, but with an extra cost. In practical terms this implies that out of 10 patients candidate for enrollment in an HF trial using an echobiomarkers only 8 to 9 can be considered eligible for presence of good quality of echocardiograms allowing to have not only interpretable but also measurable tracings.

\section{Dependence on operator's expertise}

The echocardiographic examination is highly dependent on the quality of image acquisition and analysis. Therefore, strict criteria of image acquisition, storage and analysis are required when echocardiographic data are used in a clinical trial. The American Society of Echocardiography issued some recommendations on these aspects, suggesting that only certified and trained sonographers are involved in data acquisition, and in multicenter trials core lab reading by experinced operators blinded to patient identity and study condition is recommended [27]. In addition, whenever possible a quantitative approach to image analysis should be used. In fact, several quantitative approaches have been recently proposed to evaluate ultrosound biomarkers with an operator-independent, quantitative approach for instance to assess left ventricular function with 2D speckle tracking technology [28] This will increase the precision of the method and reduce the sample size required to achieve the required statistical power of a trial [27].

\section{Lack of sufficient outcome data}

Although a large number of observational studies support the use and prognostic values of several echocardiographic markers of HF, we still miss prospective randomized trials based on echo parameters as a guide to treatment. When this has been done in other fields, results have not been always in line with the expectation and conventional wisdom. For instance PROSPECT study did not confirm that mechanical dyssynchrony with echo is associated to better outcome with CRT therapy [29]; COURAGE did not show that ischemia-driven revascularization improves prognosis over optimal medical therapy in patients with stable angina [30]; and STICH trial did not show that myocardial viability is associated to better prognosis in revascularized subjects with left ventricular dysfunction over medically treated patients [31].

It is obvious at this point that we need stronger evidence from prospective randomized outcome data before we can use echocardiography to guide our therapy choices in heart failure.

\section{Conclusion}

An integrated ultrasound assessment with echocardiographic and lung ultrasound, in resting conditions and even better during stress [32], can provide a spectrum of pathophysiological and hemodynamic information, which can conceivably be mirrored in selective, personalized, tailored therapeutic decisions (Figure 1).

The concept of the application of biomarkers as a guide to therapy is certainly an interesting one, which has stood the test of time. Not all HF patients with the same clinical picture were created equal, and NP assessment identifies higher and lower risk subgroups, which may help in guiding a different level of treatment intensity. We have learned in the past 15 years that the good clinician needs little help in starting an appropriate therapy of HF patient, but even the best clinician needs help in tailoring 


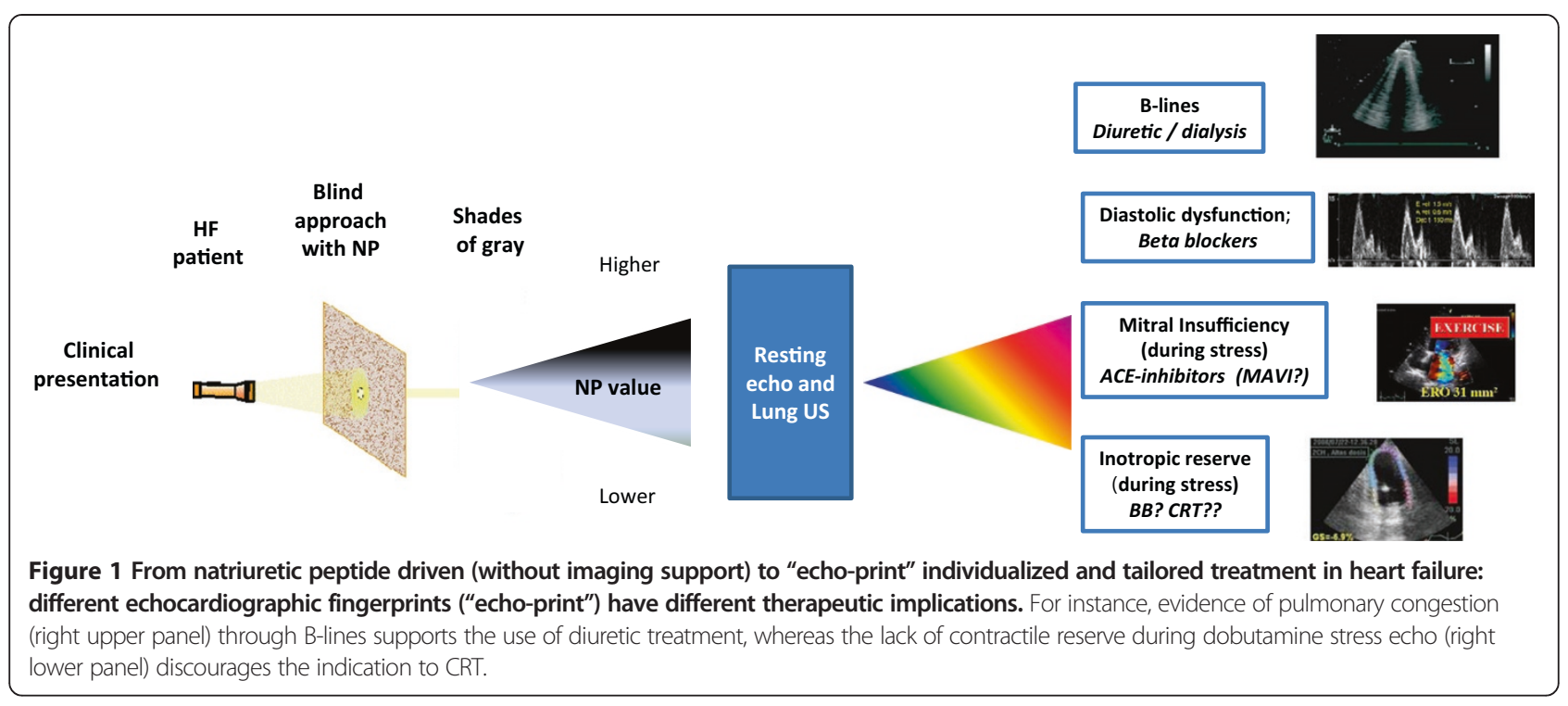

the best therapy in the HF patient to prevent acute decompensation or catastrophic complications. Many attempts in these directions including the simple NPguided therapy met only limited success with uncertain impact on mortality. On the light of the evidences presented, this cannot be considered surprising since the increase in NP is a monotonous response to a variety of different patho-physiological input conditions and, furthermore, it evokes a rather monotone output response with intensification of drug treatment. This simple and straightforward diagnostic and therapeutic algorithm can be beneficial in some patients, neutral in others, and detrimental in a subset. For instance, an increase in NP can be associated with accumulation of extra-vascular lung water, which is a sign of impending acute heart failure. If this is the case, an higher dose of loop diuretics will improve symptoms. However, if no lung congestion is present, diuretics will show no benefit and even harm. It is only a combined clinical, bio-humoral (for instance with evaluation of renal function) and echocardiographic assessment which may unmask the pathophysiological (and possibly therapeutic) heterogeneity underlying the same clinical and NP picture. Increase in B-lines will trigger increase of loop diuretics (or dialysis); the marked increase in mitral insufficiency (at baseline or during exercise) will lead to increase in vasodilators and to consider mitral valve repair; the presence of substantial inotropic reserve during stress will give a substantially higher chance of benefit to beta-blocker or CRT therapy [33-35]. To each patient its own therapy, not with a "blind date" with symptoms and NP and carpet bombing with drugs, but with an open-eye targeted approach on the mechanism predominant in that individual patient. A monocular, specialistic, unidimensional approach to HF can miss its pathogenetic and clinical complexity, which only can be overcome with an integrated, versatile and tailored approach. This is a rational clinical strategy today, but it is also a roadmap for future research, which should promote outcome studies with echo-driven therapy compared with the standard approach. At least one large-scale, prospective, randomized trial is already in progress in high-risk chronic kidney disease patients with heart failure and renal insufficiency and on dialysis-the LUST Trial (Lung water by UltraSound guided Treatment to prevent death and cardiovascular complications in high-risk end-stage renal disease patients with cardiomyopathy) [36]. The results of this study will be crucial eventually to incorporate B-lines into our clinically oriented diagnostic algorithms. Another single-center trial comparing the outcome of Blines driven therapy versus standard therapy in ambulatory outpatients is ongoing [37]. At this point, the stage is set for prospective trials comparing outcome in standard (or NP-based) [38] versus echo-driven tailored therapy of HF, moving from a blind, bio-humoral, one-fits-all approach to an open-eye, imaging-guided, therapeutically versatile approach to the patient with HF. In the management of HP patient, even the best cardiologist needs help - but the help provided by NP is costly, pathophysiologically ambiguous, with clear additional economic burden and unclear benefit of outcome. The "peptide-diuretic

Table 2 Biomarkers in heart failure

\begin{tabular}{ccc}
\hline What we have & What we need \\
\hline Clinical presentation & $\begin{array}{c}\text { Physical } \\
\text { exam + chemistry } \\
\text { Biomarkers }\end{array}$ & $\begin{array}{c}\text { Safe and low cost } \\
\text { Imaging }\end{array}$ \\
$\begin{array}{ccc}\text { Natriuretic peptides } \\
\text { Oneatment }\end{array}$ & $\begin{array}{c}\text { Echo-print } \\
\text { Onersonalized } \\
\text { and tailored }\end{array}$ \\
$\begin{array}{c}\text { Evidence for } \\
\text { echo-print }\end{array}$ & Proof of concept & Proof of efficacy \\
\hline
\end{tabular}


reflex" can even be detrimental, as the oculo-stenotic reflex of an anatomy-driven coronary revascularization. We need a better way to titrate and personalize therapy in our HF patient (Table 2). It is up to the cardiology and echocardiography community to build the missing evidence required to shift the practice of HF from art of clinicians to evidence- based tailored and individualized treatment of HF guided by low cost portable radiationfree imaging techniques $[39,40]$.

\section{Abbreviations}

ADHF: Acute decompensated heart failure; AHA/ACC: American heart association/American College of Cardiology; BNP: Brain natriuretic peptide; CRT: Cardiac resynchronization therapy; ESC: European Society of Cardiology; EF: Ejection fraction; HF: Heart failure; LV: Left ventricular; NP: Natriuretic peptides; NT-proBNP: N-terminal prohormone of brain natriuretic peptide; RCT: Randomized Clinical Trials.

\section{Competing interests}

The author(s) declare that they have no competing interests.

\section{Authors' contributions}

MCS conceived the study and drafted the manuscript which was critically reviewed by AS, FLL and MM. All authors read and approved the final manuscript.

Received: 10 April 2014 Accepted: 7 July 2014

Published: 18 July 2014

\section{References}

1. Go AS, Mozaffarian D, Roger VL, Benjamin EJ, Berry JD, Borden WB, Bravata DM, Dai S, Ford ES, Fox CS, Franco S, Fullerton HJ, Gillespie C, Hailpern SM, Heit JA, Howard VJ, Huffman MD, Kissela BM, Kittner SJ, Lackland DT, Lichtman JH, Lisabeth LD, Magid D, Marcus GM, Marelli A, Matchar DB, McGuire DK, Mohler ER, Moy CS, Mussolino ME, et al: Executive summary: Heart Disease and stroke statistics-2013 update: a report from the American Heart Association. Circulation 2013, 127:143-152

2. Fiuzat M, O'Connor CM, Gueyffier F, Mascette AM, Geller NL, Mebazaa A, Voors AA, Adams KF, Piña IL, Neyses L, Muntendam P, Felker GM, Pitt B, Zannad F, Bristow MR: Biomarker-guided therapies in heart failure: a forum for unified strategies. J Card Fail 2013, 19:592-599.

3. Vasan RS: Biomarkers of cardiovascular disease: molecular basis and practical considerations. Circulation 2006, 113:2335-2362.

4. Metra M, Teerlink JR, Voors AA, Felker GM, Milo-Cotter O, Weatherley B, Dittrich $\mathrm{H}$, Cotter $\mathrm{G}$ : Vasodilators in the treatment of acute heart failure: what we know, what we don't. Heart Fail Rev 2009, 14:299-307.

5. Tang WH, Francis GS, Morrow DA, Newby LK, Cannon CP, Jesse RL, Storrow AB, Christenson RH, Apple FS, Ravkilde J, Wu AH, National Academy of Clinical Biochemistry Laboratory Medicine: National Academy of Clinical Biochemistry Laboratory Medicine practice guidelines: clinical utilization of cardiac biomarker testing in heart failure. Circulation 2007, 116:e99-e109.

6. McMurray JJ, Adamopoulos S, Anker SD, Auricchio A, Böhm M, Dickstein K, Falk V, Filippatos G, Fonseca C, Gomez-Sanchez MA, Jaarsma T, Køber L, Lip GY, Maggioni AP, Parkhomenko A, Pieske BM, Popescu BA, Rønnevik PK, Rutten FH, Schwitter J, Seferovic P, Stepinska J, Trindade PT, Voors AA, Zannad F, Zeiher A, ESC Committee for Practice Guidelines: ESC Guidelines for the diagnosis and treatment of acute and chronic heart failure 2012: The Task Force for the Diagnosis and Treatment of Acute and Chronic Heart Failure 2012 of the European Society of Cardiology. Developed in collaboration with the Heart Failure Association (HFA) of the ESC. Eur Heart J 2012, 33:1787-1847.

7. Jessup M, Abraham WT, Casey DE, Feldman AM, Francis GS, Ganiats TG, Konstam MA, Mancini DM, Rahko PS, Silver MA, Stevenson LW, Yancy CW: 2009 focused update: ACCF/AHA guidelines for the diagnosis and management of heart failure in adults: a report of the American College of Cardiology Foundation/American Heart Association Task Force on Practice Guidelines: developed in collaboration with the International Society for Heart and Lung Transplantation. Circulation 2009, 119:1977-2016.

8. Araújo JP, Azevedo A, Lourenço P, Rocha-Gonçalves F, Ferreira A, Bettencourt $P$ : Intraindividual variation of amino-terminal pro-B-type natriuretic peptide levels in patients with stable heart failure. Am J Cardiol 2006, 98:1248-1250.
9. Troughton RW, Frampton CM, Yandle TG, Espiner EA, Nicholls MG, Richards AM: Treatment of heart failure guided by plasma aminoterminal brain natriuretic peptide (N-BNP) concentrations. Lancet 2000, 355:1126-1130.

10. Jourdain $P$, Jondeau G, Funck F, Gueffet P, Le Helloco A, Donal E, Aupetit JF, Aumont MC, Galinier M, Eicher JC, Cohen-Solal A, Juillière Y: Plasma brain natriuretic peptide-guided therapy to improve outcome in heart failure: the STARS-BNP Multicenter Study. J Am Coll Cardiol 2007, 49:1733-1739.

11. Pfisterer $M$, Buser $P$, Rickli $H$, Gutmann $M$, Erne $P$, Rickenbacher $P$, Vuillomenet A, Jeker U, Dubach P, Beer H, Yoon SI, Suter T, Osterhues HH, Schieber MM, Hilti P, Schindler R, Brunner-La Rocca HP; TIME-CHF Investigators: BNP-guided vs symptom-guided heart failure therapy: the Trial of Intensified vs Standard Medical Therapy in Elderly Patients With Congestive Heart Failure (TIME-CHF) randomized trial. JAMA 2009, 301:383-392.

12. Lainchbury JG, Troughton RW, Strangman KM, Frampton CM, Pilbrow A, Yandle TG, Hamid AK, Nicholls MG, Richards AM: N-terminal pro- B-type natriuretic peptide-guided treatment for chronic heart failure: results from the BATTLESCARRED (NT-proBNP-Assisted Treatment to Lessen Serial Cardiac Readmissions and Death) trial. J Am Coll Cardio/ 2009, 55:53-60.

13. Januzzi JL Jr, Rehman SU, Mohammed AA, Bhardwaj A, Barajas L, Barajas J, Kim HN, Baggish AL, Weiner RB, Chen-Tournoux A, Marshall JE, Moore SA, Carlson WD, Lewis GD, Shin J, Sullivan D, Parks K, Wang TJ, Gregory SA, Uthamalingam S, Semigran MJ: Use of amino-terminal pro-B-type natriuretic peptide to guide outpatient therapy of patients with chronic left ventricular systolic dysfunction. J Am Coll Cardiol 2011, 58:1881-1889.

14. Berger R, Moertl D, Peter S, Ahmadi R, Huelsmann M, Yamuti S, Wagner B, Pacher R: N-terminal pro-B-type natriuretic peptide-guided, intensive patient management in addition to multidisciplinary care in chronic heart failure a 3-arm, prospective, randomized pilot study. J Am Coll Cardiol 2010, 55:645-653.

15. Desai AS: Are Serial BNP Measurements Useful in Heart Failure Management? Serial Natriuretic Peptide Measurements Are Not Useful in Heart Failure Management: The Art of Medicine Remains Long. Circulation 2013, 127:509-516.

16. Shah MR, Califf RM, Nohria A, Bhapkar M, Bowers M, Mancini DM, Fiuzat M, Stevenson LW, O'Connor CM: The STARBRITE trial: a randomized, pilot study of B-type natriuretic peptide-guided therapy in patients with advanced heart failure. J Card Fail 2011, 17:613-621.

17. Eurlings LW, Van Pol PE, Kok WE, Van Wijk S, Lodewijks Van Der Bolt C, Balk AH, Lok DJ, Crijns HJ, Van Kraaij DJ, De Jonge N, Meeder JG, Prins M, Pinto YM: Management of chronic heart failure guided by individual $\mathrm{N}$-terminal pro-B-type natriuretic peptide targets: results of the PRIMA (Can Pro-brain-natriuretic peptide guided therapy of chronic heart failure Improve heart failure morbidity and mortality?) study. J Am Coll Cardiol 2010, 56:2090-2100.

18. Persson $H$, Erntell H, Eriksson B, Johansson G, Swedberg K, Dahlström U: Improved pharmacological therapy of chronic heart failure in primary care: a randomized Study of NT-proBNP Guided Management of Heart Failure-SIGNAL-HF (Swedish Intervention study-Guidelines and NTproBNP AnaLysis in Heart Failure). Eur J Heart Fail 2011, 12:1300-1308.

19. Pascual Figal DA, Domingo M, Casas T, Gich I, Ordoñez Llanos J, Martínez P, Cinca J, Valdés M, Januzzi JL, Bayes Genis A: Usefulness of clinical and NT-proBNP monitoring for prognostic guidance destabilized heart failure outpatients. Eur Heart J 2008, 29:1011-1018.

20. Anwaruddin S, Lloyd-Jones DM, Baggish A, Chen A, Krauser D, Tung R Chae $C$, Januzzi JL Jr: Renal function, congestive heart failure, and amino-terminal pro-brain natriuretic peptide measurement: results from the ProBNP Investigation of Dyspnea in the Emergency Department (PRIDE)Study. J Am Coll Cardiol 2006, 47:91-97.

21. Taneja AK, Gaze D, Coats AJS, Dumitrascu D, Spinorova L, Collinson P, Roughton M, Flather MD, on behalf of the SENIORS Investigators: Effects of Nebivolol on biomarkers in elderly patients with heart failure. Int J Cardiol 2014, doi:10.1016/j.ijcard.2014.05.018. [Epub ahead of print].

22. Savarese G, Trimarco B, Dellegrottaglie S, Prastaro M, Gambardella F, Rengo G, Leosco D, Perrone-Filardi P: Natriuretic Peptide-Guided Therapy in Chronic Heart Failure: A Meta-Analysis of 2,686 Patients in 12 Randomized Trials. PLoS One 2013, 8:e58287.

23. Savarese G, Musella F, D'Amore C, Vassallo E, Losco T, Gambardella F, Cecere M, Petraglia L, Pagano G, Fimiani L, Rengo G, Leosco D, Trimarco B, Perrone-Filardi $P$ : Changes of natriuretic peptides predict hospital admissions in patients with chronic heart failure: a meta-analysis. JACC Heart Fail 2014, 2:148-158.

24. Tsao CW, Vasan RS: Diagnosis: Biomarkers of cardiovascular outcomes-bonanza or bias? Circulation 2013, 9:381-382. 
25. Konstam MA, Gheorghiade M, Burnett JC Jr, Grinfeld L, Maggioni AP, Swedberg K, Udelson JE, Zannad F, Cook T, Ouyang J, Zimmer C, Orlandi C, Efficacy of Vasopressin Antagonism in Heart Failure Outcome Study With Tolvaptan (EVEREST) Investigators: Effects of oral tolvaptan in patients hospitalized for worsening heart failure: the EVEREST Outcome Trial. JAMA 2007, 297:1319-1331.

26. Douglas PS, Garcia MJ, Haines DE, Lai WW, Manning WJ, Patel AR, Picard MH, Polk DM, Ragosta M, Ward RP, Weiner RB: ACCF/ASE/AHA/ASNC/HFSA/ $\mathrm{HRS} / \mathrm{SCAl} / \mathrm{SCCM} / \mathrm{SCCT} / \mathrm{SCMR} 2011$ Appropriate Use Criteria for Echocardiography. A Report of the American College of Cardiology Foundation Appropriate Use Criteria Task Force, American Society of Echocardiography, American Heart Association, American Society of Nuclear Cardiology, Heart Failure Society of America, Heart Rhythm Society, Society for Cardiovascular Angiography and Interventions, Society of Critical Care Medicine, Society of Cardiovascular Computed Tomography, and Society for Cardiovascular Magnetic Resonance Endorsed by the American College of Chest Physicians. J Am Coll Cardiol 2011, 57:1126-1166.

27. Gottdiener JS, Bednarz J, Devereux R, Gardin J, Klein A, Manning WJ, Morehead A, Kitzman D, Oh J, Quinones M, Schiller NB, Stein JH, Weissman NJ, American Society of Echocardiography: American Society of Echocardiography recommendations for use of echocardiography in clinical trials. J Am Soc Echocardiogr 2004, 17:1086-1119.

28. Mor-Avi V, Lang RM, Badano LP, Belohlavek M, Cardim NM, Derumeaux G, Galderisi M, Marwick T, Nagueh SF, Sengupta PP, Sicari R, Smiseth OA, Smulevitz B, Takeuchi M, Thomas JD, Vannan M, Voigt JU, Zamorano JL: Current and evolving echocardiographic techniques for the quantitative evaluation of cardiac mechanics: ASE/EAE consensus statement on methodology and indications endorsed by the Japanese Society of Echocardiography. Eur J Echocardiogr 2011, 12:167-205.

29. Chung ES, Leon AR, Tavazzi L, Sun JP, Nihoyannopoulos P, Merlino J, Abraham WT, Ghio S, Leclerca C, Bax JJ, Yu CM, Gorcsan J 3rd, St John Sutton M, De Sutter J, Murillo J: Results of the Predictors of Response to CRT (PROSPECT) trial. Circulation 2008, 20:2608-2616. 117.

30. Weintraub WS, Spertus JA, Kolm P, Maron DJ, Zhang Z, Jurkovitz C, Zhang W, Hartigan PM, Lewis C, Veledar E, Bowen J, Dunbar SB, Deaton C, Kaufman S, O'Rourke RA, Goeree R, Barnett PG, Teo KK, Boden WE, COURAGE Trial Research Group, Mancini GB: Effect of PCI on quality of life in patients with stable coronary disease. N Engl J Med 2008, 359:677-687.

31. Bonow RO, Maurer G, Lee KL, Holly TA, Binkley PF, Desvigne Nickens $P$, Drozdz J, Farsky PS, Feldman AM, Doenst T, Michler RE, Berman DS, Nicolau JC, Pellikka PA, Wrobel K, Alotti N, Asch FM, Favaloro LE, She L, Velazquez EJ, Jones RH, Panza JA, STICH Trial Investigators: Myocardial Viability and Survival in Ischemic Left Ventricular Dysfunction. N Engl J Med 2011, 364:1617-1625.

32. Picano E, Pellikka PA: Stress echo applications beyond coronary artery disease. Eur Heart J 2014, 35:1033-1040.

33. Ciampi Q, Pratali L, Citro R, Piacenti M, Villari B, Picano E: Identification of responders to cardiac resynchronization therapy by contractile reserve during stress echocardiography. Eur J Heart Fail 2009, 11:489-496.

34. Da Costa A, Thévenin J, Roche F, Faure E, Roméyer-Bouchard C, Messier M, Convert G, Barthélemy JC, Isaaz K: Prospective validation of stress echocardiography as an identifier of cardiac resynchronization therapy responders. Heart Rhythm 2006, 3:406-413.

35. Ciampi Q, Villari B: Role of echocardiography in diagnosis and risk stratification in heart failure with left ventricular systolic dysfunction. Cardiovasc Ultrasound 2007, 5:34.

36. Picano E, Gargani L: Ultrasound lung comets: the shape of lung water. Eur J Heart Fail 2012, 14:1194-1196.

37. Tufaro V, Fragasso G, Ingallina G, Fisicaro A, Marini C, Loiacono F, Margonato A, Agricola E: Usefulness of lung ultrasound in the outpatient management of chronic heart failure patients: preliminary results of multicenter prospective randomized study. Eur Heart J 2013, 34(suppl.1):5058.

38. Troughton R, Michael Felker G, Januzzi JL Jr: Natriuretic peptide-guided heart failure management. Eur Heart J 2014, 35:16-24.

39. Picano E, Vañó E, Rehani MM, Cuocolo A, Mont L, Bodi V, Bar O, Maccia C, Pierard L, Sicari R, Plein S, Mahrholdt H, Lancellotti P, Knuuti J, Heidbuchel H, Di Mario C, Badano LP: The appropriate and justified use of medical radiation in cardiovascular imaging: a position document of the ESC
Associations of Cardiovascular Imaging, Percutaneous Cardiovascular Interventions and Electrophysiology. Eur Heart J 2014, 35:665-672.

40. Dini FL, Rosa GM, Fontanive P, Santonato V, Napoli AM, Ciuti M, Di Bello V: Combining blood flow and tissue Doppler imaging with $\mathrm{N}$-terminal pro-type $B$ natriuretic peptide for risk stratification of clinically stable patients with systolic heart failure. Eur J Echocardiogr 2010, 11:333-340.

doi:10.1186/1476-7120-12-27

Cite this article as: Scali et al.: The potential value of integrated natriuretic peptide and echo-guided heart failure management. Cardiovascular Ultrasound 2014 12:27.

\section{Submit your next manuscript to BioMed Central and take full advantage of:}

- Convenient online submission

- Thorough peer review

- No space constraints or color figure charges

- Immediate publication on acceptance

- Inclusion in PubMed, CAS, Scopus and Google Scholar

- Research which is freely available for redistribution

Submit your manuscript at www.biomedcentral.com/submit
C) Biomed Central 